\title{
Fakültenin geliştirilmesi: Lisans diş hekimliği eğitmenlerinin görev ve yeterlikleri
}

\author{
Funda Akaltan(0000-0001-6744-6312) ${ }^{\alpha}$ \\ Selcuk Dent J, Diş Hekimliği Eğitimini Yeniden Düşünmek - Özel Sayı
}

(Doi: 10.15311/selcukdentj.568439)

Basvuru Tarihi: 21 Mayıs 2019 Yayına Kabul Tarihi: 01 Ağustos 2019

\begin{abstract}
Öz
Fakültenin geliştirilmesi: Lisans diş hekimliği eğitmenlerinin görev ve yeterlikleri
\end{abstract}

\begin{abstract}
Fakültelerin geliştirilmesi; değişen öğrenim ve eğitim modelleri, mesleki uygulamalar ve materyallerdeki sürekli gelişimin sonucu olarak kaçınılmazdır. Dental eğitmenler lisans diş hekimliği eğitimine destek sağlayan önemli kişilerdir. Eğitim ve öğretim başta olmak üzere, müfredat geliştirme gibi birçok görev ve sorumluluğu üstlenirler. Bu makalede günümüz diş hekimliği fakülteleri için dental eğitmenin görevleri ve iyi bir eğitmen olabilmeleri için gereken yeterlikleri ile temel müfredat geliştirme aşamaları sunulmaktadır. Uzmanlık, doktora veya öğretim üyesi ünvanlarını almak, kendiliğinden eğitim becerilerinin kazanılmasını sağlamaz. Eğitmenler; sadece kendi öğretmenlerinin geçmişte kullandıkları yöntemlere inandıklarında, eğitim gelişemeyecektir. Eğitimle ilgili yeterliklerin öğrenilmesi ve geliştirilmesi gerekir. Eğitmenlerin sadece öğretme, öğrenme, değerlendirme gibi mikro düzeydeki değil, müfredat gelişimi, kurum, sağlık sistemi gibi alanlarda makro düzeydeki eğitim yeterliklerine de intiyaçları vardır.
\end{abstract}

\section{ANAHTAR KELIMELER}

Diş hekimliği eğitimi, fakültenin geliştirilmesi, eğitmen yeterlikleri, eğitmen görevleri

\begin{abstract}
Faculty development: Roles and competences for educators of undergraduate dental students

Development of faculties is inevitable because of changing in learning and teaching strategies and improvements of dental materials and treatments. Dental educators are important people who contribute to the development of every aspect of dental education. They assume lots of roles and responsibilities including curriculum development, teaching and education. This article presents common roles for educators of undergraduate dental students and the competences needed to be effective educators; and the basic procedures relating curriculum development. Being a lecturer, profesional expert or faculty member do not automatically ensure having good teaching expertise. Education has no chance to develop if educators only believe in methods of their old teachers. It is necessary to be aware of the competencies of dental educators. Educators need to have macro level competences such as educational programme and curriculum matters togehter with educational principles and strategies, student issues and assessment competences that relate to the micro-level of education.
\end{abstract}

\section{KEYWORDS}

Dental education, faculty development, educator competences, educator roles

Eğitim; ahlaki ve manevi bir görevdir; çünkü sadece anlama ve kavrama değil, aynı zamanda özveri ve sorumlulukla uğraşır; sadece zeka değil azim ve iradeyi de etkiler ve şekillendirir; yalnızca aklı değil, kalbi de geliştirmeyi hedefler. Mükemmel eğitimin; eleştirel ve açık bakış açısı, geniş ilgi ve ruh cömertliğini cesaretlendirmeye ilham verme gücü

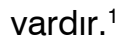

Başarılı bir eğitimin anahtarı bilgi ve deneyimleri aktarabilmektir. Her biri kendi alanında uzman olan sağlık çalışanları, eğitmen olduklarında bilgi ve becerileri başkalarına nasıl aktaracaklarını öğrenirler. Geçmişte akademik olarak başarıı ve klinik becerilerde ustalaşmış olan herkesin iyi eğitmen olacağı sanılıyordu. Oysa ki; günümüzde dünyanın çeşitli ülkelerinde klinik bir beceriyi bilmek ve uygulamak ile o bilgi ya da beceriyi öğretmenin birbirinden tamamen farklı şeyler olduğu bilinmektedir. ${ }^{1}$

\footnotetext{
${ }^{\alpha}$ Ankara Üniversitesi Diş Hekimliği Fakültesi, Protetik Diş Tedavisi Anabilim Dalı, Ankara
} 
Lisans diş hekimliği eğitiminin başarısı için öğrenciler, fakülte ve müfredat ögeleri üzerinde durmak ve bu konulardaki sorunlara çözüm önerileri getirmek kaçınılmazdır ${ }^{1}$. Eğitmenlerin kalite ve kantite açısından yeterlikleri esastır ve fakültelerin geliştirme programları eğitim becerileri ve bilgilerinin güncellenmesine hizmet eder. ${ }^{2}$ Dental müfredat çoğu fakültede aşırı yüklü olup, klinik pratiği ile ilişkilendirme açısından kusurludur. Müfredatın eleştirel düşünme ve probleme dayalı öğrenme üzerine yapılan çalışmaları da kapsaması gerekir. ${ }^{3}$

Dünyadaki tüm tıp ve diş hekimliği okulları geleneksel olarak öğretim üyelerinin eğitim şekillerini sorgulamaktan ve uygulamalardaki hataları ortaya çıkarmaktan kaçınmıştır. ${ }^{3}$ Eğitimin değiştirilebilmesi, değişen öğrenci jenerasyonu ve çağdaş eğitim modellerine adapte edilebilmesi için öğretim üyelerinin eğitim işini birincil görevleri olarak algılamaları ve karşılıklı etkileşimli öğretme yöntemleri hakkında eğitim almaları gerekir. ${ }^{3}$

Günümüz diş hekimliği öğrencilerini bilgilendirmek, yönlendirmek ve ilham vermek için eğitmenlerin yenilikçi öğretme yöntemleri, entegre içerikleri, yeterliğe-dayalı öğrenimi, güvenilir sonuçları olan değerlendirmeleri, güncel simülasyon teknolojilerini en iyi şekilde kullanmaları ve interprofesyonel uygulamalar ile hayat boyu öğrenme konularına hakim olmaları beklenir. ${ }^{1,4-6}$

\section{Dental Eğitmenlerin Görev ve Yeterlikleri}

Diş hekimliği eğitmenleri; dental eğitimin her yönüyle gelişimine katkı sağlayan değerli insanlardır. ${ }^{7}$ Lisans diş hekimliği eğitiminde, hepsi son derece önemli olan birçok görev ve sorumlulukları vardır. Bunun yanı sıra, eğitimin iyileşmesini daha iyi destekleyebilmeleri için eğitmenlerin geliştirilmesi konusuna ne yazık ki; çok az yer verilmektedir.

Dikkat edilmesi gereken ilk konu; dental eğitmenlerin görev ve yeterliklerinin tanımlanmasıdır; çünkü bu unsurlar fakülte gelişim planının kapsamı ve içeriğini belirler. Eğitmenlerin görevleri; eğitimdeki değişiklik ve gelişmeler, sağlık sistemleri ve intiyaçları, politik zorunluklar ve kurumsal gereksinimler gibi faktörlerden etkilenir. ${ }^{8-11}$ Eğitmenlerin yeterlikleri ise üstlenecekleri görevlere uygun olarak şekillenir. Eğitmenlerin bireysel olarak her alanda olmasa da, spesifik görevleriyle ilgili alanlarda yeterli olmaları gerekir. ${ }^{12} \mathrm{Bu}$ durum, etkili bir eğitmen olabilmek için minimum gereksinimleri karşılayacak çekirdek yeterliklerin varlığı ile ilgili bir soru akla getirmektedir.

\section{Eğitmenlerin Görevleri}

Dünyadaki eğitim hareketlilikleri; diş hekimliği çalışanlarının gelişimlerini etkilemiştir. Yeterliğe dayalı yaklaşımın benimsenmesi, mezunların yeterli, kanıtla beslenen ve güvenli tedavi hizmeti vererek toplumun ihtiyaçlarını karşılamalarını gerektirmektedir. Kurumsal işler (akademik politika, finans) ve dış faktörler (ulusal ağız diş sağlığı, politikalar) diş hekimliği eğitimi ve dolayısıyla dental eğitmenleri de etkiler. ${ }^{7}$

Öğretme, araştırma ve klinik uygulamalar; literatürde en çok tartışılan eğitmen görevleridir. ${ }^{12-14}$ Bazı eğitmenler yönetim ve politika üreten görevlerde çalıştıklarından, idari görevler de birçok çalışmada tanımlanmıştır. ${ }^{15,16}$ Bununla birlikte görevlerde eşitlik de söz konusu değildir; bazı eğitmenler klinisyen olmayıp, klinik eğitim ve uygulamada görev almaz, "para-klinik" görevler (patoloji, istatistik, etik gibi) üstlenirler. Yükseköğrenim ortamı dışında çalışan pratisyenler de klinik eğitimi üstlenebilir ${ }^{17}$ ve kendilerini gözlemciden ziyade eğitmen olarak düşünürler. Şartlara bakılmaksızın, dental eğitmenin en önemli görevi; öğretim ve öğrencinin gelişimine katkı sağlamaktır. "Öğretim” anahtar görev olarak yer almaktadır. Araştırma, yönetim ve tedavi üretmek de eğitmenin görevleri arasında yer alabilir (Şekil 1). ${ }^{7}$ 


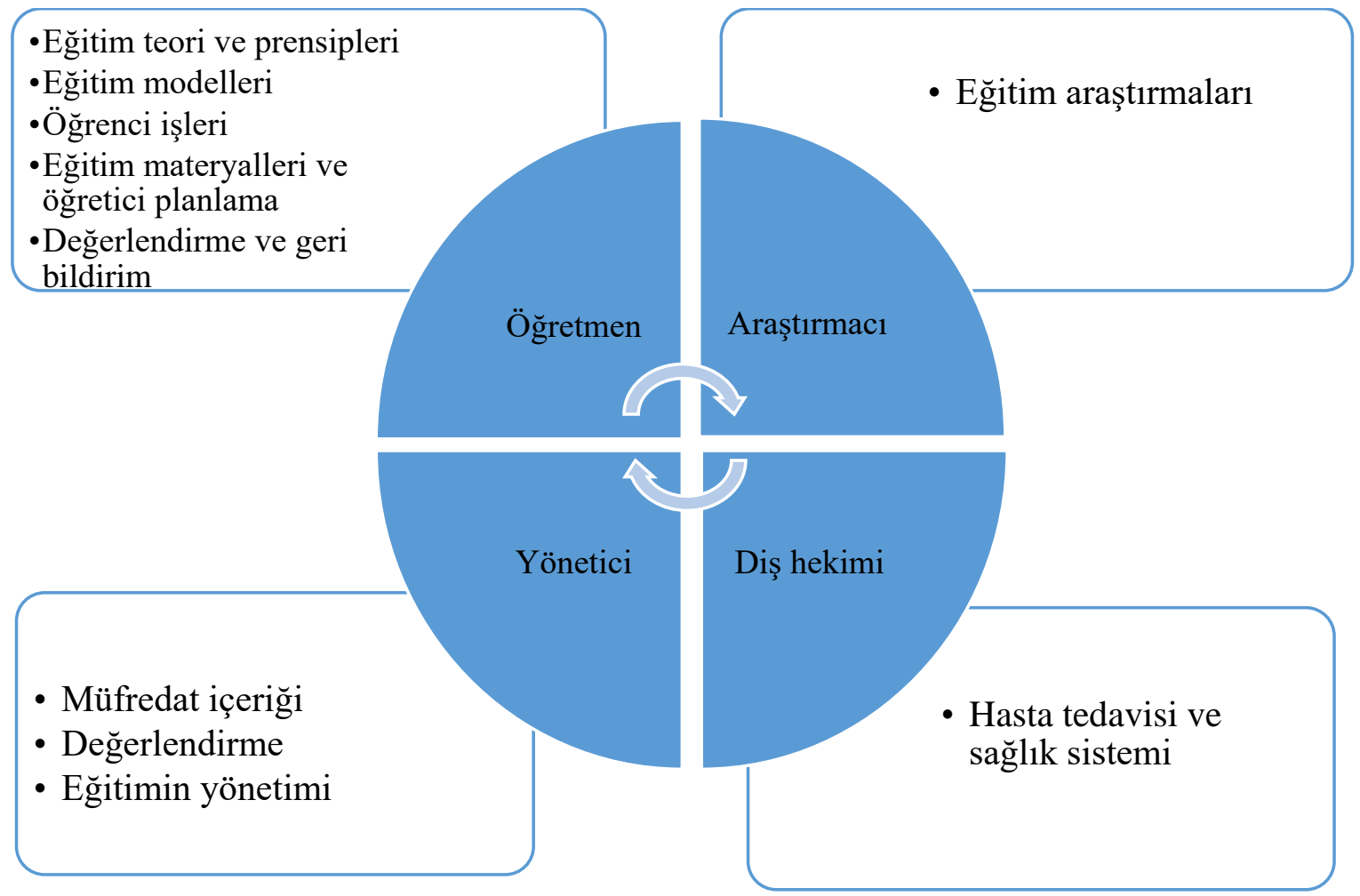

Şekil 1. Dental eğitmen görevleri

\section{Eğitmen-öğretmen}

Dental eğitmenler; farklı öğretim görevleri ile sınıflar, laboratuvarlar ve fakülte dışındaki/toplum destekli klinikler gibi ortamlarda çalışıllar. ${ }^{16,18}$ Tek bir eğitim ortamında bile, eğitmenlerin öğrencileri desteklemek için birkaç görevi üstlenmeleri gerekir. Küçük grup çalışmalarında, eğitmenler hem "öğrenimi kolaylaştııı" olarak öğrencilerin bir araya gelmesini ve grup içindeki tartışmalarını destekler; hem de "bilgi üretici" olarak öğrencilerin tartışmalarını ilerletebilmelerine yardımcı olur. Eğitmenlerin içerik uzmanlığı; öğrencilerin bilgilerini iyileştirir ve yanlışlarını düzeltir. ${ }^{19}$

Dental eğitmenlerin hem çalışıkları alanda uzman olmaları hem de iyi iletişim becerilerine sahip olmaları gerekir. ${ }^{20}$ Öğrencilere yapıcı geri bildirim verebilmek; etkili iletişim becerileri oluşturmayı sağlayan bir tutumdur. Öğrenciler hastalarıyla pozitif iletişim kurmayı; klinikte eğitmenlerinin yaklaşım ve davranışlarını gözlemleyerek geliştirirler. ${ }^{21}$ Öğrenciler; bu gizli müfredat üzerinden, eğitmen rol modelleri sayesinde profesyonel davranışlar ve tutumlar geliştirirler. Bu nedenle de gözetmenlik yaparken rol model oluşturma; klinik ortamda "öğretim" görevinin önemli bir parçasıdır.

Dental eğitmenin görevlerindeki diğer önemli bir tutumu; kanıta dayalı klinik uygulamadır. Kanıta dayalı tedavinin; klinik uygulamaların kalitesini iyileştirmesi²2 ve mezun diş hekimlerinin kanıtı; klinik pratiğinde uygulamaları gerekir. ${ }^{23}$ Eğitmenlerin, öğrencilerin eleştirel düşünme becerilerini geliştirmelerini desteklemeleri önemlidir. ${ }^{12,15}$

Öğretim görevleri; klinik ortamları içinde ve dışındaki öğrenim içeriklerini kapsar. Eğitmenlerin görevleri; bilgi üretmek, öğrenci öğrenimine gözetmenlik yapmak ve desteklemek, öğrencilerin bilgi ve yeterliklerini geliştirmelerine yardımcı olmak ve kolaylaştırmaktır. ${ }^{13}$ 


\section{Eğitmen-araştırmacı}

Eğitmenler; yeni bilgileri geliştirmek, mesleklerine yaymak ve klinik pratiğine kanıtı uygulamak zorundadır. ${ }^{8}$ Üniversitelerinde 2 alanda araştırma kanıtı oluştururlar: (1)Araştırmaları öğretimleriyle buluşturup, öğrencilerinin kanıta dayalı klinik pratiği yapmalarını sağlarlar. (2) Öğretim yöntemlerinde eğitim ile ilgili araştımaların sonuçlarından yararlanırlar.

Kanıta dayalı klinik uygulamalar; araştırma ile öğretim ve uygulamaların ilişkisini ortaya koyar. Üniversitelerdeki dental eğitmenlerin sadece araştırma sonuçlarını kullanmak değil, araştırma bulgularını üretmeleri de beklenir. Üniversite eğitmenleri için kariyer ilerlemeleri ve yükseltmeleri; sahip oldukları araştırmalar, yayınlar ve ödüllerdeki gelişmelerine bağlıdır. ${ }^{10}$ Bazı ülkelerdeki öğretim kalitesi kariyer yükseltmeleri için belirleyici bir unsur olarak kabul edilir. ${ }^{24}$ Eğitmen için gereken araştırma miktarı kariyeri ve çalışma alanıyla ilgili olsa da, eğitmenlerin öğretim ve araştırma görevlerini dengede tutmaları beklenir.

Eğitmen-araştıııılar; eğitim araştırmalarından kazanılan bulguların hem olgucu (positivist) hem de yorumlayıcı (interpretivist) araştırmalardan geldiğini unutmamalıdır. ${ }^{25}$ Nitel çalışmaların kalitesini değerlendirme işlemi; bilimsel değerlendirmeye güvenmez. ${ }^{26}$

\section{Eğitmen-yönetici}

Yöneticilik; birçok eğitmen için zorunlu bir görevdir. Öğretimin bir gereği olarak, eğitmenlerin çoğu herhangi bir dönemde yönetimde (öğretimin organize edilmesi gibi) yer alırlar. ${ }^{15}$ Klinik uygulama eğitiminde yer alan eğitmenler aynı zamanda hastaları ve sağlık sistemini de denetler; araştırmadan sorumlu olan eğitmenler ise araştırma projelerini, süreci ve araştırma fonunu yönetirler. ${ }^{12,20}$ Dental eğitimdeki gelişmeler; eğitim ve klinik uygulamaların kalitesini garanti etmek için sistematik bir süreci gerektirir. ${ }^{9}$ Eğitimdeki liderlik ve yönetim intiyaçlarına karşılık, eğitmenlerin eğitimdeki değişiklik ve gelişmeler için gerekli becerilere de sahip olması gerekir. ${ }^{13,27}$

\section{Eğitmen-diş hekimi}

Öğrenciler teorik bilgilerini klinikteki gerçek durumlarla ilişkilendirdiklerinde daha etkili öğrenirler. ${ }^{13}$ Hastanın tedavisi ve sağlık sisteminin anlaşılması; öğrencilerin mesleki sorumluluklarını daha iyi geliştirmelerini sağlar. Bu nedenle de eğitmenlerin diş hekimliği mesleğine ve tedavi içeriklerine yönelik donanıma sahip olmaları gerekir. Üniversite kliniklerinde eğitim verenlerin hasta tedavisine de katılmaları avantaj sağlar; çünkü öğrencinin klinik uygulamada yetersiz kalması durumunda eğitmenin tedaviyi üstlenmesi veya müdahale etmesi gerekebilir. Eğitmenin buradaki görevi; öğrenciyi sadece gözlemlemek değil, problemle baş etme konusunda da ders vermektir ve böylece öğrencinin klinik çözümler konusunda gelişimini de sağlar.

Dental eğitmenlerin görevlerini 3 kısımda özetlemek mümkündür: ${ }^{6}(1)$ Müfredat içinde, (2) Kurum içinde ve (3) Lisans eğitimindeki diğer görevler.

1. Müfredat içindeki görevler

- Öğrenci öğrenimini desteklemek, öğrencilerin farklı yeterlikleri geliştirmelerine yardımcı olmak için bir seri eğitim, değerlendirme ve geri bildirim yöntemini kullanmak

- Pozitif öğrenme ortamını oluşturmak ve teşfik etmek

- Dersleri, modülleri veya müfredatı planlamak ve geliştirmek 
- Öğrencilerin kayıt ve seçim sürecinde bulunmak

2. Kurum içindeki görevler

- Fakülte ve eğitimin geliştirilmesinde yönetim ve liderlik rollerini üstlenmek

3. Eğitimdeki diğer görevler

- Ağız sağlığına katkı sağlayan ulusal ve uluslararası profesyonel kurumlarda çalışmak

- Diş hekimliği eğitimindeki eğitim uygulamaları ve politikasının bilgilendirilmesi için araştırma ve yenilikleri yönetmek

\section{Eğitmenlerin Yeterlikleri}

Eğitmenlerin görevlerini yerine getirebilmeleri için yeterliklerinin üzerinde durmak gerekir. Eğitmen olarak göreve başladıklarında eğitim prensipleri konusunda bilgiye sahip olmalı, öğretme ve ilişkili görevler konularındaki becerilerini geliştirmelidirler. ${ }^{28}$ Dental eğitmenlerin eğitim programlarının amacl; yeterlik seviyesini elde etmek için esas eğitim yeterliklerini kazanmalarına yardımcı olmaktır. Bu eğitim süreci; eğitmenler belirgin yeterlik kazanana ve eğitim uygulamalarında uzmanlaşana kadar devam eder. Dental eğitmenlerin eğitimdeki gelişim ve yeniliklere öncülük etmeleri, yeni başlayan eğitmenlerin eğitim pedagojisinde yeterliğe ulaşmalarını teşfik edip desteklemeleri gerekir. Eğitim programlarının eğitmenler için ustalık veya uzmanlık seviyelerini amaçlamasına ihtiyaç yoktur; ancak programlarında, eğitmenlerin sürekli eğitim içinde olmaları ve profesyonel gelişimlerini sürdürmeleri gereğini vurgulamaları beklenir. Sürekli eğitim içinde olmaları; eğitmenlerin eğitim kariyerleri süresince, bilgi ve beceri kaybı sorunu yaşamaları ile başedebilmelerini ve eğitim pratiklerini iyileştirmelerini kolaylaştıır.

"Yeterli olmak" mezunların daha ileri uygulama ve gelişmeye ihtiyacı olmadığını göstermez. Bilgi ve beceri kullanılmadığında kötüleşir. Sık kullanmama veya bilim ve teknolojideki gelişmeler, kariyer gelişimi gibi dış faktörler bireysel yeterlikte veya bir görevi yerine getirmek için gereken yeterlikler arasında uyumsuzluk doğurabilir. Bireyin genel performansı bir sene sonunda \% 92 azalabilirken, yeterliğini kazanabilmesi için ne kadar süre gerektiği bildirilmemiştir. ${ }^{29}$

Eğitmenler; öğrencilerin sadece yeterlik durumlarını elde etmek değil, mezun olduklarında, profesyonel yeterliklerini muhafaza ederek, mesleklerinde daha ileri seviyede hizmet vermelerini sağlamalıdırlar. Bireyler görevlerini etkili bir şekilde yerine getirmek için gelişimlerine devam etmelidirler. ${ }^{7}$

Eğitmenlerin görevi bilgi üreten kişi olmaktan çok, öğrencilerin öğrenmeleri ve mesleki yeterliklerini geliştirebilmeleri için destek ve geri bildirim sağlayan, öğrenimi kolaylaştıııc kişilere dönüşmek olmalıdır. Farklı eğitim stratejilerini öğrenerek ve uygulayarak öğrencileri farklı öğrenim seviyelerinde desteklemelidirler. ${ }^{7}$

\section{Yeterlik çeşitleri}

1990'dan bu yana lisans diş hekimliği eğitimindeki ileri gelişmelere rağmen, dental eğitmenlerin yeterlikleri üzerinde hala çalışılmaktadır. Pedogoji (eğitim prensipleri, öğrenme çeşitleri, öğretme stratejileri vb), değerlendirme ve müfredatı ilgilendiren eğitim yeterlikleri tüm eğitmenler için esastır. ${ }^{12,13,16}$ Bu yeterlikler; eğitmenlerin öğretimin eğitim esaslarını anlamalarına yardımcı olarak, "nasıl öğretilir" konusuna destek sağlar. ${ }^{28}$ Ancak araştırma ve yönetim 
görevleriyle ilgili yeterlikler incelenmemiş; sadece klinik eğitimle ilgili içerikler öne çıkarılarak, dental eğitmenlerin eğitim görevlerini etkileyen klinik dışı görevleri de olabileceği konusu inmal edilmiştir.

Eğitmenlerin araştırma, yönetim, tedavi ve profesyonellik gibi diğer görevlerinde etkili olabilecek bazı standartlar oluşturulmuştur. ${ }^{25,30}$ Molenaar ve ark.ları ${ }^{31}$ eğitmenlerin her konuda yetkin olmaları gerektiğini ileri sürmüştür. Bununla birlite içerik ve kültür öğretim ve öğrenimi büyük oranda etkiler. ${ }^{7,18}$ Farklı eğitim yeterliklerine ulaşabilmek için farklı içerik ve kültüre sahip eğitmenlerin fakülte kadrosunda yer alması gerekir.

Eğitmenlerin yeterlik alanları; eğitim teorileri, prensipleri ve yöntemleri, değerlendirme ve geri bildirim, müfredat ve değerlendirme, yönetim, sağlık sistemi ve profesyonellik olarak bildirilmiştir. Eğitmenlerin tek başlarına her alanda yetkin olmaları gerekmez; ancak spesifik olarak görev yaptıkları alanda uzman olmaları beklenir. ${ }^{12}$

Görevleri veya içeriklerine bakılmaksızın, eğitmenlerin genel olarak sahip olması gereken yeterlikleri şu şekilde gruplanmıştır: (1) Eğitim teori ve prensipleri, (2) Eğitim modelleri, (3) Öğrenci işleri, (4) Eğitim materyalleri ve öğretici planlama, (5) Ölçme-değerlendirme ve geri bildirim, (6) Müfredat, (7) Değerlendirme, (8) Eğitim araştırmaları, (9)Eğitim yönetimi, (10) Kalite üretimi, (11) Hasta tedavisi ve sağlık sistemi, (12) Eğitimde profesyonellik. ${ }^{7}$

İlk beş alandaki yeterlikler; eğitimin mikro düzeyini gösterir. Altı ve yedinci alandaki yeterlikler ise makro düzeydir. Sekizinci alan yeterliği; öğretimi desteklemek üzere, eğitimi kullanma, geliştirme ve üretmeyle ilişkilidir. On, onbir ve onikinci alandaki yeterlikler; yönetim, liderlik, kalite üretimi ile hasta tedavisi ve sağlık sistemini ilgilendirir. Son alandaki yeterlik ise iyi bir eğitmen olabilmek için gerekli olan kişisel ve profesyonel davranışları belirler. Dental eğitmenlerin yeterlik alanları ve yeterlik içerikleri; örnekleriyle birlikte Tablo 1'de sunulmuştur. ${ }^{7}$ 
Tablo 1. Dental eğitmenler için yeterlik alanları ve yeterliklerin örnekleriyle listesi ${ }^{7}$

\begin{tabular}{|c|c|c|}
\hline Alan & Yeterlik & Örnekler \\
\hline \multirow[t]{7}{*}{$\begin{array}{l}\text { Eğitim teorileri ve } \\
\text { prensipleri }\end{array}$} & $\begin{array}{l}\text { Öğrenme } \\
\text { teorileri }\end{array}$ & $\begin{array}{ll}\text { - } & \text { Eğitimde genel prensipler ve öğrenme teorileri } \\
\text { - } & \text { İnsananışsal, kavramsal, yapıcı, insancil vb) } \\
& \text { psikomotor ve duygusal alanlar) ve eğitimdeki } \\
& \text { uygulamaları (Bloom's taxonomy) } \\
\text { - } & \text { Yetikinler nasıl öğrenir } \\
\text { - } & \text { Eğitmen-merkezli öğrenme } \\
\text { - } & \text { Öğrenci-merkezli öğrenme } \\
\text { - } & \text { Hasta-merkezli öğrenme } \\
\text { - } & \text { Deneysel öğrenme } \\
\text { - } & \text { Kendi kendine-yönlendirilen öğrenme } \\
\text { - } & \text { Eğitim teorilerinin uygulanmasi/kanıt }\end{array}$ \\
\hline & $\begin{array}{l}\text { Öğrenme çeşitleri ve öğrenme } \\
\text { yaklaşımları }\end{array}$ & $\begin{array}{l}\text { - } \quad \text { Öğrenme çeşitleri (Kolb’s ögrenme çeşitleri) } \\
\text { - } \quad \text { Ögrenme yaklaşımları (yüzeyel, stratejik ve } \\
\text { derinlemesine öğrenme) }\end{array}$ \\
\hline & Öğrenme ortamı & $\begin{array}{l}\text { - Müfredattaki öğrenme ortamı (öğretme ve } \\
\text { öğrenme ortamı, klinik ortamı) } \\
\text { - Müfredat dışındaki öğrenme ortamı (müfredat } \\
\text { dişı aktiviteler) } \\
\text { - Farklı öğrenme ortamları için gereken fiziksel } \\
\text { özellikler }\end{array}$ \\
\hline & Yansiyan uygulamalar & $\begin{array}{l}\text { - } \quad \text { Yansımanın prensipleri } \\
\text { - Uygulama sonrasındaki yansımalar } \\
\text { - } \quad \text { Uygulama içindeki yansımalar }\end{array}$ \\
\hline & Mentorluk ve koçluk & $\begin{array}{ll}- & \text { Mentorluk } \\
\text { - } & \text { Koçluk } \\
\text { - } & \text { Danışmanlık }\end{array}$ \\
\hline & $\begin{array}{l}\text { Çağdaş ögretme ve öğrenme } \\
\text { yöntemleri }\end{array}$ & 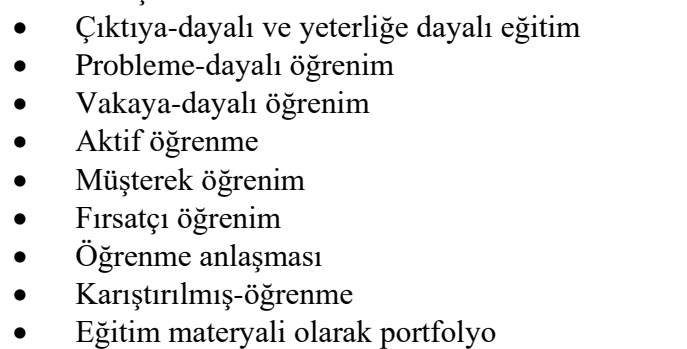 \\
\hline & Eğitim stratejileri ve süreçleri & $\begin{array}{ll}\text { - } & \text { Öğretim stratejileri nasıl seçilir, geliştirilir ve } \\
\text { - } & \text { değiştirilir } \\
\text { - } & \text { Güili ögrenli eğitim ortamı nasıll oluşturulur } \\
\text { - } & \text { Öğrenim ihtiyaçlarının değerlendirilmesi ve } \\
& \text { analizi } \\
\text { - } & \text { İçeriğin tanımlanması, seçimi ve sıralanması } \\
\text { - } & \text { Öğrencilerin dersleri ve ders bileşenlerini } \\
& \text { anlamasını sağlamak } \\
\text { - } & \text { Öğrenmeyi kolaylaştırmak (öğrenmeyi } \\
& \text { cesaretlendirmek ve motive etmek, öğrencileri } \\
\text { biraraya getirmek, çatışmalarla ilgilenmek) }\end{array}$ \\
\hline \multirow[t]{3}{*}{ Eğitim modelleri } & Büyük grup öğretimi & $\begin{array}{ll}\text { - } & \text { Büyük grup öğretme yöntemleri } \\
\text { - } & \text { Bir dersin hazırlanması ve anlatılması }\end{array}$ \\
\hline & Küçük grup öğretimi & $\begin{array}{ll}\text { - } & \text { Grupların tipleri ve küçük grup yöntemleri } \\
\text { - } & \text { Gruba yardımcı olmak } \\
\text { - } & \text { İşlevsiz grupların geliştirilmesi } \\
\text { - } & \text { Akran-yardımıyla öğrenim ve tutorial (özel ders) } \\
& \text { grupları }\end{array}$ \\
\hline & Bire bir öğretme & $\begin{array}{ll}\text { - } & \text { Gözetim ve denetim } \\
\text { - } & \text { Bire bir eğitim desteği ve rehberlik } \\
\text { - } & \text { Hasta-bașı öğretim }\end{array}$ \\
\hline
\end{tabular}


Klinik ortamda öğretim

Fakülte-diş1/toplumdestekli/çalışma alanına-dayalı öğretim

Mesleklerarası/multidisipliner öğretim

\section{Öğrenci işleri}

Eğitim materyalleri ve öğretici planlama geri bildirim Öğrencilerin problemleri ve
zorlukları

Öğrencileri için destek

Özel ihtiyaçları olan öğrenciler

Öğrenme kaynakları, eğitimsel medya ve materyalleri

Öğretici planlama

Değerlendirme prensipleri

Değerlendirme yöntemleri ve araçları

Değerlendirme kalibrasyonu

Performans değerlendirmesi

Kendini-değerlendirme

Geri bildirim

Müfredat geliştirme

Müfredatın uygulamaya konması
- Bilgi ve uygulamanın entegrasyonu

- Klinik/uygulamalı becerilerin öğretim

- Klinik eğitimde teknik problemler ve hatalar

- Klinikte rol modeller

- Simüle hastalar

- Eğitimde hastanın yer alması

- Dental fakülte-dışı öğretim (üniversite hastanesi dışındaki toplum kliniklerinde veya diğer kliniklerde yapılan ancak geleneksel dental eğitmenlerle koordine edilen öğretim)

- Klinikte denetim ve gözetim

- Klinikte rol modeller

- Mesleklerarası öğretim (sağlık ve sosyal bakım alanındaki bir veya daha fazla meslekten öğrencilerin bir arada öğrenim gördükleri ortamlarda, işbirlikçi ve hastaya-dayalı tedavi üretilen öğretim)

- Öğrenci problemleri ve öğrenme zorluklarının tipleri

- İşlevsiz davranışlar

- Öğrenci problemlerini tanımlama ve yönetme

- Öğrencilerin gelișimini desteklemek

- Başarısız öğrenciyi desteklemek (1slah etme)

- Özel ihtiyaçları olan öğrencilerin tipleri

- Özel ihtiyaçları olan öğrencilerin eğitiminin desteklenmesi

- Eğitim/öğretici/öğrenme materyallerinin hazırlanması ve kullanımı

- Öğretim ve öğrenme için bilgi, öğrenme kaynakları ve eğitimsel medyanın kullanımı (klinik simülatörü, sanal öğrenme ortamı)

- Ögretici planlamanın prensipleri

- Uzaktan öğrenim

- Teknolojiyle-iyileştirilen öğrenme

- Genel değerlendirme prensipleri (değerlendirme amaçları, Miller'in piramidi)

- Öğrenci gelişiminin değerlendirilmesi (izlemeye dayalı durum belirleme ve düzey belirleme)

- Öğrenci profilleri

- Öğretimin geliştirilmesi için değerlendirmenin araç olarak kullanılması

- İyi değerlendirme uygulamaları

- Değerlendirme araçlarının tipleri, planlaması ve geliştirilmesi

- Psikometrik yöntemler (gerçeklik, güvenirlik)

- Standart uygulama, tekniğin belirlenmesi ve kriterlerin kullanımı

- Değerlendirme aracı olarak portfolyo kullanımı

- Eğitmenlerin kalibrasyonu

- Değerlendirmenin kalibrasyonu

- Çıktıya-dayalı/yeterliğe-dayalı değerlendirme

- Performans değerlendirmesi

- Çalışma esaslı değerlendirme

- Kendini izleme

- Kendini değerlendirme

- Değerlendirme ve geri bildirim

- Yapici geri bildirim verme

- Kendi performansını fark etmeyen öğrencileri yönetme

- Müfredat felsefesi, hedefler ve yapı (ürün, süreç, araştırma)

- Problemin tanımı ve ihtiyaçların değerlendirilmesi

- Müfredat tasarımı, planlaması ve organizasyonu

- Müfredatın uygulamaya konmasında destek, kaynaklar ve engeller 
Program ve ders geliștirilmesi

\section{Değerlendirme}

Eğitim araştırmaları

Eğitim yönetimi

\section{Kalite üretimi}

Hasta tedavisi ve sağlık sistemi
Eğitim programlarının değerlendirilmesi

Öğretmen ve öğretimin değerlendirilmesi

Eğitim araştırma ve yöntemleri

Araştırma bileşenleri ve süreç

Dental eğitimdeki yönetim ve organizasyon prensipleri

Liderlik ve takım çalışması

Eğitimdeki değişiklikler

Seçme ve yerleştirme süreci

Kalite üretiminde denetleme prensipleri, kalite standartları

Lokal/ulusal kalite üretimi ve mevzuatla ilgili organlar

Kalite üretiminin uygulamaya konması ve gelişimi Sağlık sistemi ve yönetimi
- Müfredatın tanıtılması ve yönetimi

- Müfredatın gözden geçirilmesi ve güncellenmesi

- Program/ders tasarımı, planlaması ve organizasyonu

- Eğitim programı/dersin yönetimi

- Eğitim programlarını değerlendirmenin genel prensipleri

- $\quad$ Eğitim bileşenlerinin değerlendirilmesi (öğretim ve öğrenim, değerlendirme, kaynak materyalleri, ders, program, müfredat)

- Denetim ve değerlendirmede öğrencilerin yer almas1

- Öğretimin akranlarca gözden geçirilmesi

- Öğretmen değerlendirmesi ve destek

- Eğitmenleri desteklemek için değerlendirme araçları

- Eğitim araştırmalarının genel prensipleri

- Nitel ve nicel yöntemler

- Araştırma bileşenleri (ortam, etik, kaynak)

- Araştırma süreci (gelliştirme, planlama, uygulamaya koyma, yorumlama, yayınlama)

- Eğitim araştırmalarını değerlendirme

- Ulusal eğitim sisteminin gözden geçirilmesi

- Avrupa yüksek eğitiminin geliştirilmesi: Bologna Süreci ve Avrupa Yüksek Eğitimi

- Eğitim çıktıları ve Avrupa yüksek öğreniminin üç düzeyinin mezun özellikleri (Bachelor, Master, Doctoral seviye)

- Dental eğitim ve diğer sağlık meslek eğitimlerinin tarihi ve gelişimi

- Lokal/ulusal/uluslararası dental eğitim içeriği, politikası, organizasyonları ve tartışma grupları

- $\quad$ Genel yönetim prensipleri (misyona-dayalı yönetim, stratejik yönetim, pazarlama, etkili yönetim)

- Genel organizasyon prensipleri (vizyon, hedefler, misyonlar, görevler, ortamlar, politikalar)

- Fakültenin yapısı ve görevleri

- Eğitim programlarının yönetimi

- Eğitim için kaynak yönetimi (bütçe ve finans, imkanlar)

- İnsan kaynakları yönetimi (çalışanların gelişimi ve eğitilmesi)

- Kültürel farklılıkların yönetimi (eşitlik, çeşitlilik, firsat)

- $\quad$ Liderlik

- $\quad$ Ekip kurulması ve ekip çalışması

- Organizasyonel değişikliğin gelişimi ve uygulamaya konulması

- Dental eğitimin değişimi ve gelişimi

- $\quad$ Öğrenci seçim yöntemleri (çok yönlü görüşmeler)

- Seçme kriterleri

- Kaliteyle ilgili terminoloji

- Denetim prensipleri, eğitim kalitesi ve standartları

- Lokal/ulusal/uluslararssı kalite üretimi

- Eğitim standartları/yönetim

- Yasal ve mevzuatla ilgili organlar

- Dental eğitim için kalite üretiminin uygulamaya konması ve gelişimi

- Sağlık sistemi ve görevi

- Kanıta-dayalı ağız sağlığı bakımı ve uygulaması

- Lokal sağlık ihtiyaçlarına duyarlık 
Sağlık bakımı kalitesi ve standartlar1

\section{Eğitimde profesyonellik}

Mesleki etik ve davranı̧̧

Profesyonelliğin gelişimi

İçerik bilgisi ve uzmanlık Klinik ve teknik beceriler

Kanıta-dayalı uygulama

Kanıta-dayalı eğitim

İletişim ve kişilerarası beceriler

Kişisel yönetim beceriler

Kariyer becerileri

Kişisel ve mesleki gelişim
- $\quad$ Tıp/sağlık alanında kültürel bakıș açısı ve sağlık bakımı açısından engeller

- Sağlık bakımının finasman

- Zayıf sağlık hizmetleri ve iyileștirilmesi

- Sağlık bakımıve hizmet kalitesi

- Klinik standartları, protokolü, politikası ve yönetimi

- Lokal/ulusal standartlar ve rehberlik

- Eğitim görevlerinde etik ve profesyonellik

- Mesleki etik, yürütme, davranış ve standartlar

- Eğitimde düzenlemeler ve güncel eğitimsel ve profesyonel gereksinimler

- Dental eğitimin özellikleri (eğitimsel görevlerde pozitif davranış modeli, öğretim hevesi, rol model)

- Dental eğitimde profesyonelliğin gelişimi

- Dental eğitime bağl1lık ve dental eğitimi savunma

- Bilim dalının bilgi ve becerileri

- Klinik muayene becerileri

- Klinik ve teknik beceriler

- Kanıta-dayalı tıp ve diş hekimliği

- Kanıta-dayalı beceriler (eleştirel değerlendirme, kanitın uygulanmasi)

- Eğitimi desteklemek ve geliştirmek için kanıtın kullanımı

- İletișim ve sunum becerileri

- Farklı milletlerle çalışma

- Değerlendirme/eleştiriye cevap

- Problem çözme ve yaratıcı düşünme

- Anlaşmazlık çözümü ve uzlaşma

- Zaman ve görev yönetimi

- Toplantının organizasyonu

- Kariyer planlaması ve gelişimi

- Denge görevleri ve çalışma yükü

- Öğretme ve öğrenme yöntemlerini güncelleme

- Kişisel ve mesleki becerileri geliştirme

- Kişisel ve mesleki gelişmeler için ajanslar ve bilgi kaynaklarının kullanımı

- Sürekli mesleki gelişim girişimi

\section{İyi Bir Eğitmende Aranan Özellikler}

Profesyonel eğitmen tutumları - tedavi kalitesi, dürüstlük, doğruluk, öğrencilere olumlu yaklaşım, öğrenciye saygı, diğer meslektaşlarla olumlu etkileşim, öğretim-eğitim, duyarlık ve destek için hevesli olma, iyi rol model olma uzmanlığın içerik ve sürecine bağlanmıştır; ${ }^{13,32}$ ancak profesyonelliğin tanımı tartışmalıdır. ${ }^{33,34}$ Profesyonelliği bütüncül anlamda görerek "akıl, eller ve kalp" yönüyle açıklamak faydalı olabilir. ${ }^{35}$

Eğitmenin "doğru işler yapması" (akıl) gerekir. Öğretim ve öğrencinin öğrenimini desteklemek için gerekli olan becerileri sergilemek üzere "işleri doğru yapması" (eller) beklenir. Son olarak, öğretme mesleğinin gereği olan davranışlara sahip olması için "doğru insan olması" (kalp) gerekir. Eğitim profesyonelliğinin profesyonel tutumlardan farklı bir birikim olarak görülmemesi; hatta eğitmenlerin çekirdek özellikleri arasında yer alması istenir. ${ }^{35}$

\section{Eğiticilerin Eğitimi}

Eğitimcilerin eğitim yeterliklerini desteklemek için "fakültenin gelişimi-geliştirilmesi" terimi kullanılır . ${ }^{36}$ Eğitmen yeterlikleri geliştirildiğinde; fakültelerin eğitim-öğretim kalitesinde de gelişim yaşanacak; hiç şüphesiz mezun yeterlikleri ve öğrenim çıktıları iyileşecektir. 
Avrupa'da diş hekimliği öğrencileri için eğitmenlerin yetiştirilmesinde kullanılacak bir müfredatta; müfredat konuları, içerik ve uygulamadaki eksiklikler şu şekilde belirlenmiştir: 6,7

1. Eğitim prensipleri: Öğretim görevi için "öğrenim teorileri” en önemli bileşendir ve eğitmenlerin bu konuda kendilerini geliştirmeleri gerekir. Öğrencilerin gözüyle eğitmenler değerlendirildiğinde, eğitmenlerin öğrenmeyi desteklemek üzere güncel teknolojileri kullanmadıkları bildirilmiştir. Bu nedenle de teknoloji destekli öğrenim, müfredatın konuları arasında yer almalıdır; ancak finansal problemler yaşayan fakülteler için bu öğrenim yöntemini kullanmak kolay olmayacaktır.

2. Diş hekimliğinde eğitim uygulamaları: Yansıııcı uygulamalar (reflective practice-bilginin başka alanlarda kullanılması ve uygulanması) klinik eğitimin önemli bir parçasıdır. Yansıtıcı uygulamalar; öğrencilerin üstü kapalı bilgilerin farkında olmalarına, derinlemesine öğrenmeyi geliştirmeden önce, teorik bilgiyle uygulamayı birleştirebilmelerine imkan sağlar. Geri bildirim; eğitmen ve öğrenci arasındaki iletişimin doğru kurulmasına dayanan önemli bir bileşendir. Eğitmenler; öğrencilerin kültürel farklııklarının da farkında olarak geri bildirim yapabilmeli ve öğrencileri tartışma gruplarına katılmaları için cesaretlendirmelidir.

3. Müfredat kalitesi ve geliştirilmesi: Eğitmenlerin; müfredat değerlendirilmesi sürecinde yer almaları ve geliştirilmesinde istekli olmaları gerekir.

4. Eğitimde profesyonellik: Eğitmenlerin öğrencileri için iyi bir rol model olmaları gerekir. Öğrenciler uygulamaları eğitmenlerinden öğrenirler ve eğitmenin sınırları eğitimin çerçevesini belirler. Öğrenciler; eğitmenlerinin hem iyi bir klinik uzman hem de iyi bir eğitmen olmalarını beklerler. Bu nedenle de profesyonellik; hem klinik açıdan hem de eğitmenlik açısından değerlendirilmelidir.

5. Optimum müfredat: Eğitmenler klinik alanlarda araştırma yapmalarına karşın, eğitimle ilgili sınırlı sayıda araştırmaya dahil olurlar. Eğitim çalışmalarında aktif olarak rol almaya bakmaksızın, öğretim yöntemlerini iyileştirmek için eğitmenlerin eğitim alanında kanıt ve iyi uygulama üretmeleri gerekir. Eğitmenlerin öğrencileri muayenehane yönetimi ve vergiler konularında eğitmeleri ve kendilerini de geliştirmeleri gerekir.

\section{Fakülte İçin Müfredat Geliştirme}

Lisans diş hekimliği klinik eğitimi; mezunların bağımsız klinik pratiğini sergileyebilecekleri şekilde istenen öğrenim çıktıları ve tüm alanlardaki yeterliklerini içeren bir müfredat gerektirir. ${ }^{37}$

\section{Müfredat geliştirme aşamaları}

Müfredat geliştirme; eğitmenlerin başlıca görevleri arasında yer almaktadır. Müfredat geliştirme yöntemleri birçok araştırmacı tarafından çalışılan bir konudur. Kern ve ark.ları ${ }^{38}$ sağlık meslekleri eğitimi alanında 6 aşamalı bir müfredat geliştirme yaklaşımı ileri sürmüştür:

1. Problemin tanımı ve genel ihtiyaçların değerlendirilmesi: Popülasyonun ağız sağlığı ihtiyaçlarınının eleştirel analizini de içeren problemin tanımlanması; topluma hizmet veren diş hekiminin ideal özelliklerinin ulusal ve uluslararası faktörler ve uygulamaları da dikkate alarak tanımı; toplumsal intiyaçları karşılamaya yönelik ulusal yaklaşımların analizi. 
2. Hedeflerin değerlendirilmesi: Hedef öğrenci grubunun ve spesifik öğrenim kurumunun ihtiyaçlarının değerlendirilmesidir.

3. Ölçülebilir amaçların geliştirilmesi: Hedefler ve amaçlar belirlenir.

4. Eğitim stratejilerinin belirlenmesi: Amaç ve hedeflere yönelik olarak eğitim yöntemleri belirlenir.

5. Uygulama aşaması: Müfredat hazırlandıktan sonra ilgili kurumların onayı alınır ve müfredat uygulandıktan sonra yaşanan sorunlar için yeni düzenlemeler yapilır.

6. Değerlendirme ve geri bildirim: Tüm dördüncü ve beşinci sınıf öğrencileri davet edilir. Öğrencilere; müfredatta genel olarak ne öğretildiği, dikey ve yatay entegrasyonlar (block and stream), klinikler, probleme dayalı öğrenim ve temel tıp eğitimi ile ilgili dersleri, simülasyon teknolojisi kullanımları ile değerlendirme yöntemleri ile ilgili açık uçlu sorular yöneltilir. Bu basamağın ikinci aşamasında, fakülte öğretim üyeleri ve asistanları dahil edilerek; eğitmenlerin yaşları, eğitim tecrübeleri, farklı müfredatlarla çalışmaları, uzmanlıkları anketle sorgulanır. Üçüncü aşamada ise fakülte dışından gelen eğitmenler ve hatta hastalardan geri bildirim alınarak, öğrenci eğitiminin çıktıları gözlenir.

\section{Müfredat seviyeleri}

Diş hekimliği müfredatı 3 seviyede ele alınır:

1. İstenen (intended) müfredat: Öğrenme çıktılarını içerir.

2. Uygulanan (implemented) müfredat: $\mathrm{Ne}$, ne zaman ve nasıl öğretileceğidir.

3. Sağlanan (attained) müfredat: Öğrencilerin neyi öğrendiği veya kazandığıdır. ${ }^{39-41}$

İnovatif öğretim yaklaşımı; uygulanan müfredat üzerinde yoğunlaşmayı gerektirir. İstenen müfredat; uygulanan müfredatı bilgilendirir; ancak uygulanan müfredat istenen müfredatın düzenlenmesi ve şekillendirilmesine katkıda bulunur. İstenen müfredatın ne kadar sağlandığını anlamak için istenen müfredatın değerlendirilmesi gerekir. Müfredatın başarılı olması için eğitmenler ve eğitmenlerin özellikleri önemlidir. ${ }^{39-41}$

\section{Diş Hekimliği Fakültelerinin Öğrenim ve Öğretim Gereklilikleri ${ }^{13}$}

- Çalışma programları, dersler, modüller ve ünitelerin amaçları ve öğrenim çıktıları açıkça ifade edilmeli; içerik ve değerlendirmeyle uyumlu olmalıdır.

- Öğrenme ve öğretme hastalar ve toplumun ağız sağlı̆ı ihtiyaçları ve öğrencilerin eğitim gerekliliklerine göre yapılmalıdır.

- Öğrenme ve öğretme öğrenci merkezli olmalıdır.

- Öğrenme ve öğretme yöntemleri; kullanıldığı ortama bakılmaksızın, amaçlarına uygun olarak, farklı öğrenme stillerini kolaylaştırmak üzere seçilmelidir.

- Öğretimde eğitim kadrosunun dikkate alınması ve öğrencilerden destek alınması önemlidir ve uygulanmalıdır.

- Fakülte üyeleri ve öğrenciler; bilgisayar ve internet kullanımı açısından yeterli olmalı ve her ikisine de kolay ulaşım sağlamalıdır. 
- Değerlendirme yöntemleri, mevcut çalışma zamanı, toplam iş yükü gibi akademik ortamla ilgili değişkenler hakkında düzenli geri bildirim alınmalıdır.

\section{Diş Hekimliği Fakültelerine Öğrenim ve Öğretim için Öneriler ${ }^{13}$}

Fakültelerin;

- öğrencilerin öğrenim intiyaçları ve öğrenim ortamlarıyla uyumlu farklı eğitim yöntemleri tercih etmesi; eğitim içeriğini ulaştırmak için sadece ders vermeye odaklanmaması,

- öğrencilerin kendi öğrenimlerinden sorumlu oldukları ve uygun rehberlik sağlanabilen bir öğrenci merkezli öğrenim kültürü oluşturması; öğrencilerin çalışmalarında aktif ve yaratıcı olmalarını teşfik etmesi ve öğrenci geri bildiriminin önemini anlama ve dikkate alınmasını sağlaması,

- eğitim sürecinin her aşamasında, konsültanlar ve uzmanlara ulaşımı sağlaması ve kaynakların paylaşımı için fırsatlar yaratması,

- eğitmenler için eğiticilerin eğitimini uygulaması ve eğitimde ödül sistemini oluşturması;

- elektronik-öğrenme ve öğretim araçlarını kullanması, internetin bilgiye ulaşım aracı olarak kullanılmasını teşfik etmesi, e-öğrenime müfredatında yer vermesi,

- öğrencilerin kritik düşünme ile yaşam boyu öğrenmeyi bir tutum olarak kazanmalarını; bilgi ve becerilerini yöneterek zaman içinde yeterliklerini geliştirmelerini teşfik etmesi,

- modüller içeren entegre ve yapılandırılmış bir müfredat uygulaması ve derslerde tekrardan kaçınması, modüllerin içinde ve arasındaki ilerleme seviyesinin açıklanmış olması,

- bilgi kaynaklarının geliştirilmesinde kanıta-dayalı yaklaşımı kullanması,

- öğrencileri öğrenmeye teşfik eden değerlendirme yöntemlerini kullanması, öğrenciler ve eğitmenler için esnek öğrenme ve değerlendirme yöntemlerini desteklemesi,

- OSCE ve yeterliğin değerlendirilmesi gibi yöntemlerin mezuniyetten önce kullanılmasını garanti etmesi beklenir.

\section{Akademik Kadroya Verilen Önem ve Öğrenci Desteği}

Akademik kadroyu oluşturan üyeler; öğrenim ve öğretme yöntemlerinin tercihini şekillendiren danışmanlar ve uzmanlardır. Eğitmenler; fakültelerin eğitim amaçlarına katılımları, öğretme başarıları ve sorumlulukları bakımından ödüllendirilmelidir. Bunun yanı sıra, sistematik olarak akran eğitmenler birbirlerinin öğretim ortamlarına girerek, eğitim hakkında geri bildirim vermelidir. Bu değerlendirme; en iyi uygulamanın öğrenilmesi açısından, eses olarak yapıcı geri bildirimler üzerinde yoğunlaşmalıdır. Öğrenciler de kendi öğrenim süreçlerine dahil edilmeli; farklı öğrenim yöntemleri ile avantaj ve dezavantajları hakkında farkındalıkları olmalıdır. Öğrenciler; medya ve teknolojiyi de içeren farklı çalışma yöntemlerini deneyimleyerek, etkili ve uygun öğrenime kavuşmaları sağlanmalıdır. Öğrencilere de derslerinde geri bildirim yapmaları ve almaları için fırsat tanınmalıdır. Diş hekimliği öğrencileri için klinik yeterlik elde etmeleri çok önemlidir. Akademik ve yardımcı eğitmen desteği bunda büyük rol oynar. Müfredat 
yapısı; öğrencilerin kişisel gelişimlerini spor ve kültürel aktivitelerle geliştirmelerine engel olmamalı; hatta teşfik etmelidir. ${ }^{6}$

\section{SONUÇ}

Eğitmenlerin yeterliklerinin iyi anlaşılması; eğitmenlerin kendi gelişimleri için gereken eğitim intiyaçlarını tanımlamalarına yardımcı olacak ve dolayısıyla da kurumların çalışanlarına destekleyici, mesleki gelişim programlarını sunmalarını sağlayacaktır. Gelecekten beklenen; eğitmenlerin dental eğitimin değişmesi ve gelişimine daha etkili katkı sağlayacak yeterliklere sahip olabilmeleridir. 


\section{KAYNAKLAR}

1. Lyon LJ, Hoover TE, Giusti L, Booth MT, Mahdavi E. Teaching Skill Acquisition and Development in Dental Education. J Dent Educ 2016; 80: 983-93.

2. Licari FW, Evans CA. Clinical and Community-Based Education in U.S. Dental Schools. J Dent Educ 2017; 81: 81-7.

3. Padmapriya T. The perspectives and perceptions of dental education in the West and an overview of dental education in India. J Education and Ethics in Dent 2015; 5: 41-6.

4. Haden NK, Andrieu SC, Chadwick DG, Chmar JE, Cole JR, George MC. The dental education environment. J Dent Educ 2006; 70: 1265-70.

5. Hendricson W, Anderson E, Andrieu S, Chadwick DG, Cole JR, George MC. Does faculty development enhance teaching effectiveness? J Dent Educ 2007; 71: 1513-33.

6. Chuenjitwongsa S, Oliver RG, Bullock AD. Competence, competency-based education, and undergraduate dental education: a discussion paper. Eur J Dent Educ 2016; 22:1-8.

7. Chuenjitwongsa S, Bullock A, Oliver RG. Roles and competences for educators of undergraduate dental students: a discussion paper. Eur J Dent Educ 2018; 22: 47-56.

8. Heflin MT, Pinheiro S, Kaminetzky CP, Mcneill D. 'So you want to be a clinician-educator. . '? designing a clinician-educator curriculum for internal medicine residents. Med Teach 2009; 31: 233-40.

9. Jones ML, Hobson RS, Plasschaert AJ, Gundersen S, Dummer P, Roger-Leroi V. Quality assurance and benchmarking: an approach for european dental schools. Eur J Dent Educ 2007; 11: 137-43.

10. Smesny AL, Williams JS, Brazeau GA, Weber RJ, Matthews HW, Das SK. Barriers to scholarship in dentistry, medicine, nursing, and pharmacy practice faculty. Am J Pharm Educ 2007; 71: 1-9.

11. Winning T, Needleman I, Rohlin M, Carrassi A, Chadwick B, Eaton K. Evidence-based care and the curriculum. Eur J Dent Educ 2008; 12: 48-63.

12. Hand JS. Identification of competencies for effective dental faculty. J Dent Educ 2006: 70: 937-47.

13. Plasschaert AJM, Manogue M, Lindh C, McLoughlin J, Murtomaa H, Nattestad A. Curriculum content, structure and ECTS for European dental schools. Part II: methods of learning and teaching, assessment procedures and performance criteria. Eur J Dent Educ 2007; 11: 125-36.

14. Scott J. So you want to be an academic? Dent Update 2003; 30: 187-93.

15. Bligh J, Brice J. Further insights into the roles of the medical educator: the importance of scholarly management. Acad Med 2009; 84: 1161-5.

16. Srinivasan M, Li S-TT, Meyers FJ, Prat DD, Collins J, Braddock C. "Teaching as a competency": competencies for medical educators. Acad Med 2011; 86: 1211-20. 
17. Smith M, Lennon M, Brook A, Robinson P. Perspectives of staff on student outreach placements. Eur J Dent Educ 2006; 10: 44-51.

18. Harden RM, Crosby J. Amee guide no 20: the good teacher is more than a lecturer - the twelve roles of the teacher. Med Teach 2000; 22: 334-47.

19. Azer SA. Challenges facing pbl tutors: 12 tips for successful group facilitation. Med Teach 2005; 27: 67681.

20. Prideaux D Alexander H, Bower A, Bower A, Dacre J, Haist S, Jolly BC. Clinical teaching: maintaining an educational role for doctors in the new health care environment. Med Educ 2000; 34: 820-6.

21. Fugill M. Tacit knowledge in dental clinical teaching. Eur J Dent Educ 2012; 16: 2-5.

22. Winning T, Needleman I, Rohlin M, Carrassi A, Chadwick B, Eaton K. Evidence-based care and the curriculum. Eur J Dent Educ 2008; 12: 48-63.

23. Cowpe J, Plasschaert A, Harzer W, Vinkka-Puhakka H, Walmsley AD. Profile and competences for the graduating european dentist -update 2009. Eur J Dent Educ 2010; 14: 193-202.

24. Dearing R. The dearing report: The National Committee of Enquiry into Higher Education, UK, 1997.

25. Bullock AD. Dental education as a social science: some implications for research. Eur J Dent Educ 2010; 14: $65-8$.

26. Guba EG, Lincoln Y. Paradigmatic controversies, contradictions, and emerging confluence. In: Denzin N, Lincoln Y, eds. Handbook of qualitative research. CA: Sage Publication, 2000: 163-88.

27. Corbet E Akinwade J, Duggal R, Gebreegziabher G, Hirvikangas H, Hysi D. Staff recruitment, development and global mobility. Eur J Dent Educ 2008; 12: 149-60.

28. McLeod PJ, Steinert Y, Meagher T, McLeod A. The abcs of pedagogy for clinical teachers. Med Educ 2003; 37: $638-44$

29. Arthur W Jr, Bennett W Jr, Stanush PL, McNelly TL. Factors that influence skill decay and retention: a quantitative review and analysis. Hum Perform 1998; 11: 57-101.

30. AoME. Professional standards (2012). Cardiff: The Academy of Medical Educators, 2011.

31. Molenaar W, Zanting A, Van Beukelen P, De Grave W, Baane JA, Bustraan J. A framework of teaching competencies across the medical education continuum. Med Teach 2009; 31: 390-6.

32. Hesketh EA, Bagnall G, Buckley EG, Friedman M, Goodall E, Harden RM. A framework for developing excellence as a clinical educator. Med Educ 2001; 35: 555-64.

33. Bostock S, Baume D. Professions and professionalism in teaching and development. In: Baume D, Popovic C, eds. Advancing practice in academic development. Abingdon: Routledge, 2016: 32-50.

34. Seery A. Ethics and professionalism in teaching. Stud Irish Q Rev 2008; 97: 183-92.

35. Easton F. Educating the whole child, "head, heart, and hands": learning from the waldorf experience. Theory into Practice 1997; 36: 87-94. 
36. Steinert $\mathrm{Y}$, Mann $\mathrm{K}$, Centeno A, et al. A systematic review of faculty development initiatives designed to improve teaching effectiveness in medical education: BEME Guide No. 8. Med Teach. 2006; 28: 497-526.

37. Burrows RS. Understanding self-assessment in undergraduate dental education. British Dent J 2018; 224: 897-900.

38. Kern DE, Thomas PA, Hughes MT. Curriculum development for medical education: a six-step approach. 2nd ed. Baltimore: Johns Hopkins University Press, 2009.

39. Schmidt WH, McKnight CC, Houang R, et al. Why schools matter: using TIMSS to investigate curriculum and learning. New York: Jossey-Bass, 2001.

40. Schmidt WH, Wang HA, McKnight C. Curriculum coher $\neg$ ence: an examination of U.S. mathematics and science content standards from an international perspective. J Curriculum Stud 2005; 37: 525-59.

41. Wang HA, Schmidt WH. History, philosophy, and sociol $\neg$ ogy of science in science education: results from the third international mathematics and science study. Sci Educ 2001; 10: 51-70.

Yazışma Adresi:

Prof. Dr. Funda AKALTAN

Ankara Üniversitesi Diş Hekimliği Fakültesi

Protetik Diş Tedavisi Anabilim Dalı

Beşevler 06560, Ankara

E-posta : akaltanfunda@gmail.com 